\title{
Microstructure Evolution of Cold Pilgering Stainless Steel Tubes
}

\author{
Jia Dai $\mathbb{D}^{1}{ }^{1}$ Wei Li, ${ }^{1}$ and Zhibing Chu ${ }^{1,2}$ \\ ${ }^{1}$ Engineering Research Center Heavy Machinery Ministry of Education, Taiyuan University of Science and Technology, \\ Taiyuan 030024, China \\ ${ }^{2}$ School of Mechanics and Civil Engineering, Jinan University, Guangzhou 510632, China \\ Correspondence should be addressed to Jia Dai; daijia@tyust.edu.cn
}

Received 7 December 2019; Revised 17 February 2020; Accepted 17 March 2020; Published 8 April 2020

Academic Editor: Gianfranco Palumbo

Copyright (C) 2020 Jia Dai et al. This is an open access article distributed under the Creative Commons Attribution License, which permits unrestricted use, distribution, and reproduction in any medium, provided the original work is properly cited.

\begin{abstract}
The 347 stainless steel tube cold rolling test was carried out by a LG60 two-roll pilger mill. The microstructure evolution was examined by microscope, SEM, and XRD tests. The finite element software DEFORM-3D has been used to simulate the pilgering process, and the obtained equivalent stress and metal flow were analyzed. The experimental results showed that the internal slip line was randomly distributed, the deformation of the inner wall was more intense than the outer wall structure, and the austenite $\gamma$ phase was transformed into the $\alpha^{\prime}$-martensitic phase. The simulation results indicated that the direction of metal flow was constantly changing, and the equivalent stress of the inner wall of the steel tube was greater than the equivalent stress of the outer wall. In addition, the slip zone of the inner wall of the characteristic section was more severe than that near the outer wall slip zone. The simulation verified the experimental results to some extent.
\end{abstract}

\section{Introduction}

In 1929, Germany Krupp Company developed 347 stainless steel by adding $\mathrm{Nb}$ to stainless steel in order to improve the mechanical stability of stainless steel and prevent the precipitation of chromium carbide. Today, 347 stainless steel tubes are commonly used in the fields of petroleum industry and thermal power generation [1]. Pilgering is an important method for producing high-performance tubes. It has the characteristics of high material utilization, large accumulated deformation in cross section, and high machining accuracy and is widely used in processing and manufacturing of various metal tubes including stainless steel, titanium alloys, and zirconium alloys [2, 3]. In view of this, domestic and foreign research scholars are studying cold pilgering, including the design of holes and equipment and the optimization of process parameters.

Lodej et al. [4] and Mulot [5] et al. used finite element simulation software Forge 3 to establish a two-roll pilgering model and analyzed changes and distributions of stress, strain, rolling force, and torque in one pass rolling process. Abe and Furugen [6] analyzed the deformation behaviour of tubes during pilgering and obtained the appropriate conditions which could ensure the surface quality of the deformed tube. Abe et al. [7] proposed a new lubrication calculation method using Reynolds's equation and formulas for the required lubrication conditions for different feeding rates, rolling speed, rolling pass, and other process parameters. Randall [8] discussed the effect of the sidewall gap on the dimensional accuracy of the deformed tube. Abe et al. [9] performed an analysis of the rolling conditions affecting the dimensional accuracy and ellipticity during the pilgering. Huang et al. $[10,11]$ used ABAQUS software to simulate the process of rolling titanium alloy tube and analyzed the force, equivalent stress, and equivalent strain. Most provided references dealt with the effects of process parameters on shape and surface accuracy of the formed tube $[12,13]$.

Results from study of cold pilgering of a 347 stainless steel pipe is presented in this paper. Two-roller pilger rolling experiment is performed by LG60 rolling mill. The obtained finished pipe is sampled at different deformation sections, and its microstructure evolution law is analyzed using metallographic microscope, SEM, and XRD. Results from finite element simulations of the process are evaluated. The metal flow and equivalent stress have been of particular interest. The study provides further explanation of the 
microstructure evolution and the differences between the inner and outer wall structures obtained by the experiment.

\section{Experiment}

2.1. Rolling Tests. The experimental tube is composed of 347 stainless steel and its microstructure is austenitic stainless steel. The chemical composition (mass fraction, (\%)) is $\mathrm{C}$ 0.056, Cr 17.42, Ni 9.32, Mn 0.81, Si 0.40, P 0.032, S 0.021, and $\mathrm{Nb} 0.63$. Its mechanical properties are given in Table 1 according to BS:347S17. The experiment was performed on a LG60 cold rolling tube mill of Shanxi Taigang Stainless Steel tube Co., Ltd. The outer diameter of the 347 stainless steel seamless tube blank before cold rolling was $\Phi 67 \mathrm{~mm}$ and the wall thickness was $6 \mathrm{~mm}$. After cold rolling, the outer diameter of the steel tube was $\Phi 38 \mathrm{~mm}$ and the wall thickness was $3 \mathrm{~mm}$.

2.2. Sample Preparations and Observation. Figure 1 shows the different deformation sections I, II, III, IV, and V of the steel tube that are sampled. The tube was continuously formed by rotary feed and die rolling. Due to the periodicity of the pilgering, the various deformation sections can be seen from Figure 1 . The relative positions and outside diameters between the different section are shown in Table 2. Section I is the prerolling tube blank, sections II, III, and IV are different deformation sections, and section $\mathrm{V}$ is the deformed stage. An arc-shaped specimen of $8 \mathrm{~mm} \times 8 \mathrm{~mm}$ was cut in five sections by wire cutting, and the axial-radial plane was used as the observation surface. Due to the small size, the sample was inlaid and fixed by the metallographic sample mounting machine using bakelite powder.

Figure 2 shows the mosaic specimen of each deformation section perpendicular to the direction of the pipe, that is, the plane composed of ND and TD (observation surface A). The mounted sample was polished and cleaned with distilled water and absolute ethanol. To prevent its surface oxidation, the cleaned sample was quickly blown dry with a blower, and it was placed in the etching solution which was aqua regia: $35 \%$ nitric acid, 15\% hydrochloric acid, and 50\% glycerol [14] to corrode its surface. In order to clearly compare the microstructure and properties of different parts, the metallographic observations were carried out at different positions of the specimen circumferential deformation from the axis. The metallographic microscope was used to observe the samples. The samples before and after rolling were observed in detail using a SEM, and it was subjected to phase analysis using an XRD. The composition of the precipitates was analyzed by an energy spectrum analyzer (EDS).

\section{Analysis of Results}

3.1. Metallographic Observations. Figure 3 is the metallographic structure of each deformation section perpendicular to the direction of the pipe, that is, the plane composed of ND and TD (observation surface A). Figure 3(f) indicates the sample selection position and observation position. $\mathrm{RD}$, $\mathrm{ND}$, and TD represent the rolling direction, the normal direction, and the tangential direction, respectively. It can be seen from Figure 3(a) that the matrix of the base material before rolling, a single austenite structure, is relatively uniform and the grain boundary is clear. At this time, the metal has not been deformed and the average grain size is about $50 \mu \mathrm{m}$. As shown in Figure 3(b), it is clearly observed that a part of the slip line as the position marks by the red wireframe in the figure appears inside the austenite grains. As the amount of deformation increases, the grains are broken. Austenite grain size is not uniform, which may cause the residual stress to increase during rolling. It could be seen from Figures 3(c), 3(d), and 3(e) that when the deformation amount is gradually added, the degree of deformation of the crystal grains is remarkably increased and the number of crystal grains in which slip deformation occurs is continuously aggrandized. The direction of the shifting line is irregularly distributed, and the austenite grain boundary becomes blurred, which is because of the complex deformation characteristics caused by the continuous rotation and feeding during pilgering.

Table 3 is a comparison of the metallographic structure of the inner and outer wall of each deformation section parallel to the direction of the pipe, that is, the surface composed of $\mathrm{ND}$ and $\mathrm{RD}$ (observation surface $\mathrm{B}$ ). It can be observed that the tube structure before the rolling is a single austenite structure and the grain boundaries are clear. As the rolling progressed, the slip lines begin to appear within the grains. And the slip direction is not the same as the rolling direction in the strip rolling, but it is irregularly distributed. With the increase of the rolling pass, the grain of the slip deformation manifolds gradually, the degree heightens remarkably, and its boundary is difficult to distinguish. At the same time, it can be seen that the deformation degree of the inner wall and the outer wall have obvious differences in the early stage of pilgering. Compared with the outer wall structure, the slip zone of the inner wall is more obvious and the deformation degree is more severe. So, we can know that the grain shredding starts first from the inner wall, and the degree deformation of the inner and the outer wall gradually becomes the same as the rolling progress.

3.2. SEM Observations. Figure 4 shows the SEM and EDS results of different deformation sections. Figure $4(\mathrm{a})$ is an SEM of section I. It can be seen that the austenite structure is uniform and the grain boundaries are apparent before rolling. Figure 4(b) is an SEM of section V. There are obvious slip lines in the grains and there is no regularity in the direction distribution. Three sites of suspected precipitates in section I and section $\mathrm{V}$ are marked as A, B, and C and their energy spectrums are analyzed. Figure 4(c) shows the results of the marked points of the SEM. From the analysis results, it can be possible to conclude that the precipitates at the abovementioned marking points are particles of niobium carbide. Numerous studies have shown that the precipitation of chromium carbide in stainless steel will increase the intergranular corrosion of stainless steel [15]. While the niobium in 347 stainless steel tends to form carbonized niobium with carbon to inhibit the opportunity of combining chromium with carbon, making it difficult to form 
TABLE 1: The mechanical properties of 347 stainless steel.

\begin{tabular}{lccc}
\hline Grade & Tensile strength $\sigma_{\mathrm{b}}(\mathrm{MPa})$ & Yield strength $\sigma_{\mathrm{s}}(\mathrm{MPa})$ & Elongation rate $(\%)$ \\
\hline 347 & $\geq 520$ & $\geq 205$ & $\geq 40$
\end{tabular}

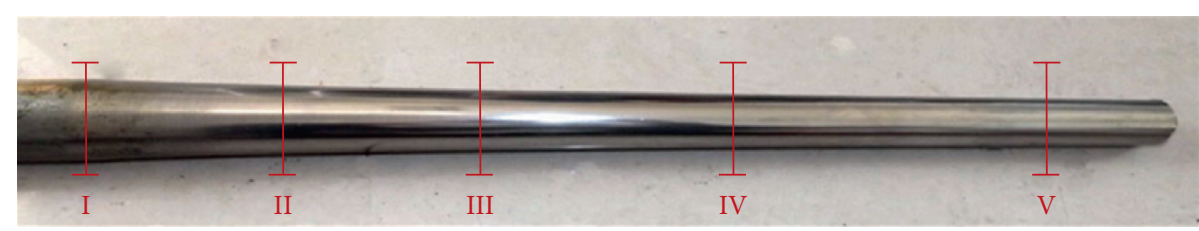

Figure 1: The deformed tube.

TABLe 2: Data of different sections of the deformed tube.

\begin{tabular}{lccccc}
\hline Section & I & II & III & IV & V \\
\hline Distance $(\mathrm{mm})$ & 0.00 & 135.00 & 408.00 & 736.50 & 951.64 \\
Outer diameter $(\mathrm{mm})$ & 67.00 & 55.71 & 42.74 & 38.45 & 38.00 \\
\hline
\end{tabular}

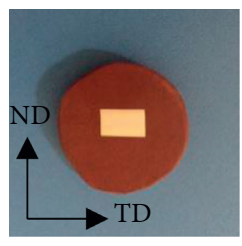

(a)

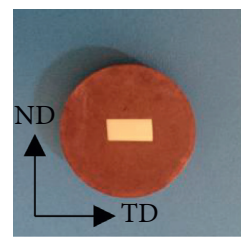

(b)

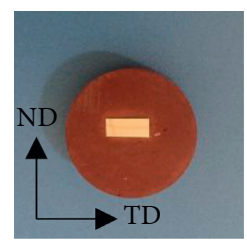

(c)

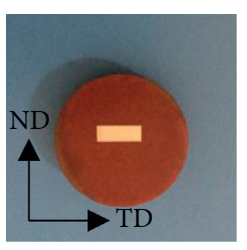

(d)

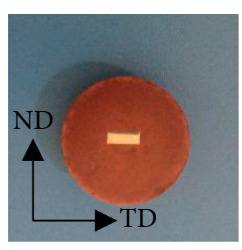

(e)

FIgURE 2: The mosaic specimen of each deformation section perpendicular to the direction of the pipe, that is, the plane composed of ND and TD (observation surface A). (a) Deformation I. (b) Deformation II. (c) Deformation III. (d) Deformation IV. (e) Deformation V.

chromium carbides at the grain boundaries. Compared with the SEM and EDS results before and after rolling, it can be seen that there are already a large number of niobium carbide particles in the tube before rolling, and it is difficult to reach the required temperature for the precipitation of niobium carbide and chromium carbide, which makes the precipitation of niobium carbide not significantly increased compared with before rolling. And there is no chromium carbide precipitation at the same time.

3.3. XRD Phase Analysis. Figure 5 shows the XRD before and after rolling. It can be seen that the 347 stainless steel used in the experiment is face-centred cubic austenite, and the diffraction planes corresponding to the three peak positions with lower stacking fault energies are fcc $\{111\}$, $\{200\}$ and $\{220\}$. Compared with the steel tube before rolling, the $\gamma\{220\}$-phase peaks disappear, but the new body-centred cubic structure peaks $\alpha^{\prime}\{110\}, \alpha^{\prime}\{200\}$, and $\alpha^{\prime}\{211\}$ appeared. In other words, $\alpha^{\prime}$-martensite is induced. The martensitic transformation takes the form of structural change through crystal shear. It stems from the fact that austenite transforms into a body-centred cubic structure [16]. As the deformation increases, $\alpha^{\prime}$-martensite nucleates at the intersection of the shear bands and produces. However, austenite stability in the cold rolling state is relatively high. The steel tube is mainly subjected to threedirection compressive stress, so less martensite is induced.
The phase change will have a direct impact on the mechanical properties of the material. The production of $\alpha^{\prime}$-martensite further explains the work hardening mechanism of the cold-rolled 347 stainless steel tube from the aspect of phase change. The austenite $\gamma$-phase diffraction peak of the deformed tube is widened because the internal residual stress becomes large during pilering and the grain refinement degree is intensified as the rolling progress.

\section{Simulations}

4.1. Numerical Modeling. A FEM was built using the LG-60 pilger mill as a prototype. Figure 6 shows the FEM of pilgering. It consists of upper and lower rolls, the tube, mandrels, and push blocks. The rollers, mandrels, and push blocks were set as rigid bodies, and the tube was set as elastoplastic bodies. Coulomb friction was selected for all friction types, and the coefficient of friction was selected to be 0.1 [17]. In order to match the transient changes in stress and strain, the simulation process was performed based on the modified Lagrangian method. The material model followed the Prandtl-Reuss flow equation and the Von Mises yield criterion and was solved using the Newton-Raphson method [18].

The material parameters can be extracted from the material library of DEFORM-3D itself. The rolling specifications are the same as the experimental rolling 


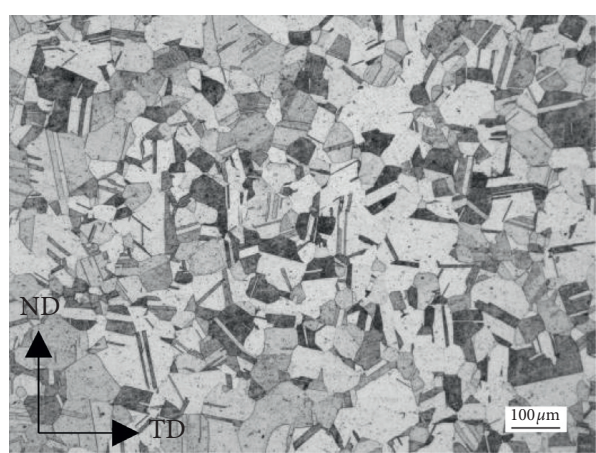

(a)

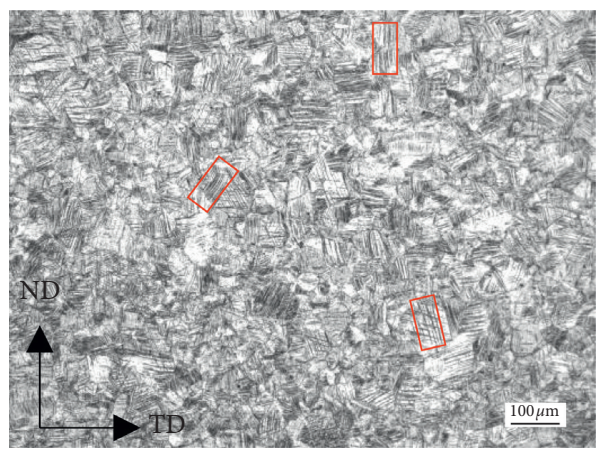

(c)

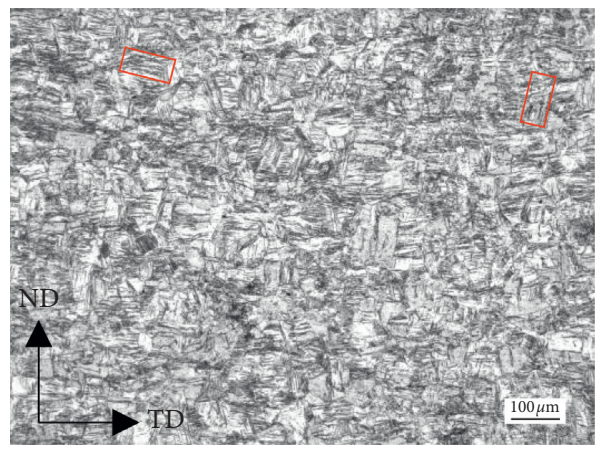

(e)

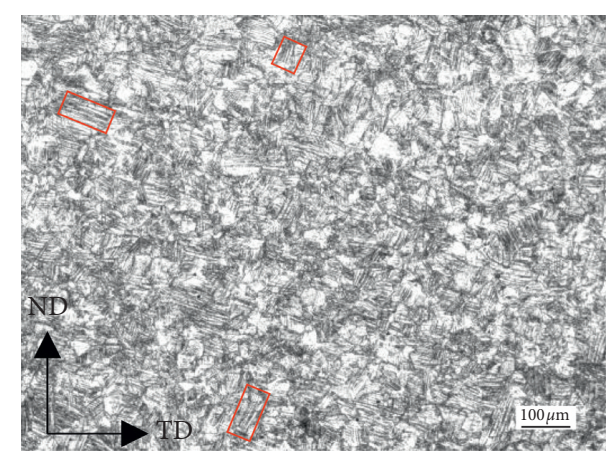

(b)

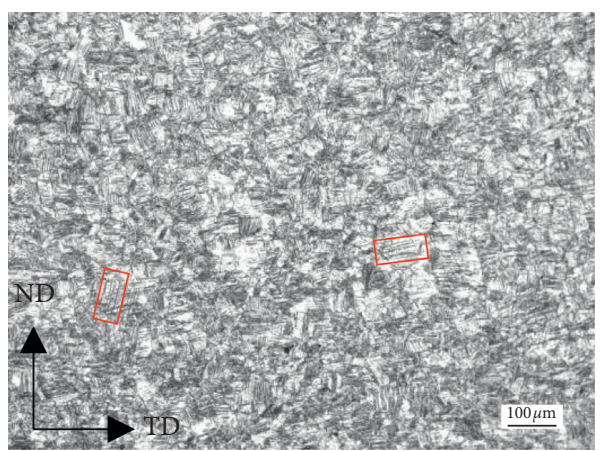

(d)

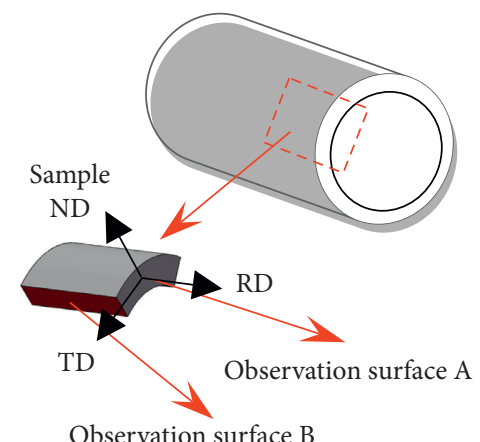

(f)

FIGURE 3: Distribution of metallographic structure observation surface (A) and observation surface of deformation section perpendicular to the direction of the pipe. (a) Section I. (b) Section II. (c) Section III. (d) Section IV. (e) Section V. (f) Observation surface of metallographic experiment.

specifications. There are 40 passes in total, the feed amount is $10 \mathrm{~mm}$, the rotation angle is $60^{\circ}$, and other basic parameters are shown in Table 4.

The wall thickness of the deformed tube was $3 \mathrm{~mm}$, the maximum grid size was set to $3 \mathrm{~mm}$ by the absolute mesh option in DEFORM so that at least one grid was ensured in the radial direction where the wall thickness of the deformed tube was the smallest. If the grid is too small, it will greatly increase the computation of software operations, but the calculation accuracy will not be significantly improved.

When the pilgering mill is in operation, the upper and lower rollers reciprocally move at random and roll on the rack through the driving gear. The translational and rotational motions are considered to be uniform motions. Roller speed is evenly decelerated to zero in the front and rear limit positions and then uniformly accelerated in the opposite direction. According to the distance of rack travel and the times of rack travel, the translational speed of the roller was calculated to be $1903.28 \mathrm{~mm} / \mathrm{s}$, and the angular velocity of the roll was $11.329 \mathrm{rad} / \mathrm{s}$.

4.2. Analysis of Simulation Results. Figure 7 indicates the deformation zone in simulation. The finite element postprocessing module intercepted the equivalent stress change of different deformation sections. In accordance with the experimental test program, the steel deformation section intercepts the metal flow of five deformation sections I, II, III, IV, $\mathrm{V}$ at the same position. The simulation results were compared with the experimental results to analyze and verify the microstructure evolution. 
TABLE 3: Microstructure comparison of the inner and outer wall of the deformed section of the steel tube (observation surface B).

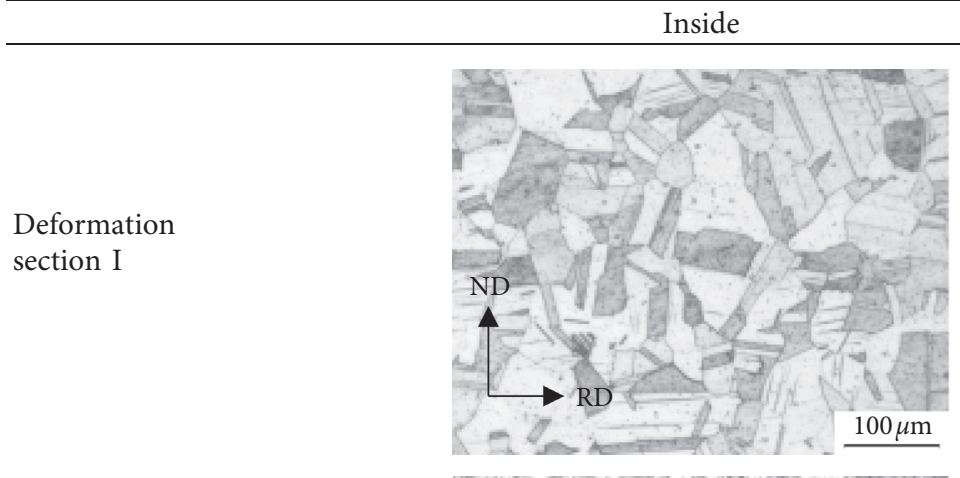

Deformation section II

Deformation section III

Deformation section IV

Deformation section $\mathrm{V}$
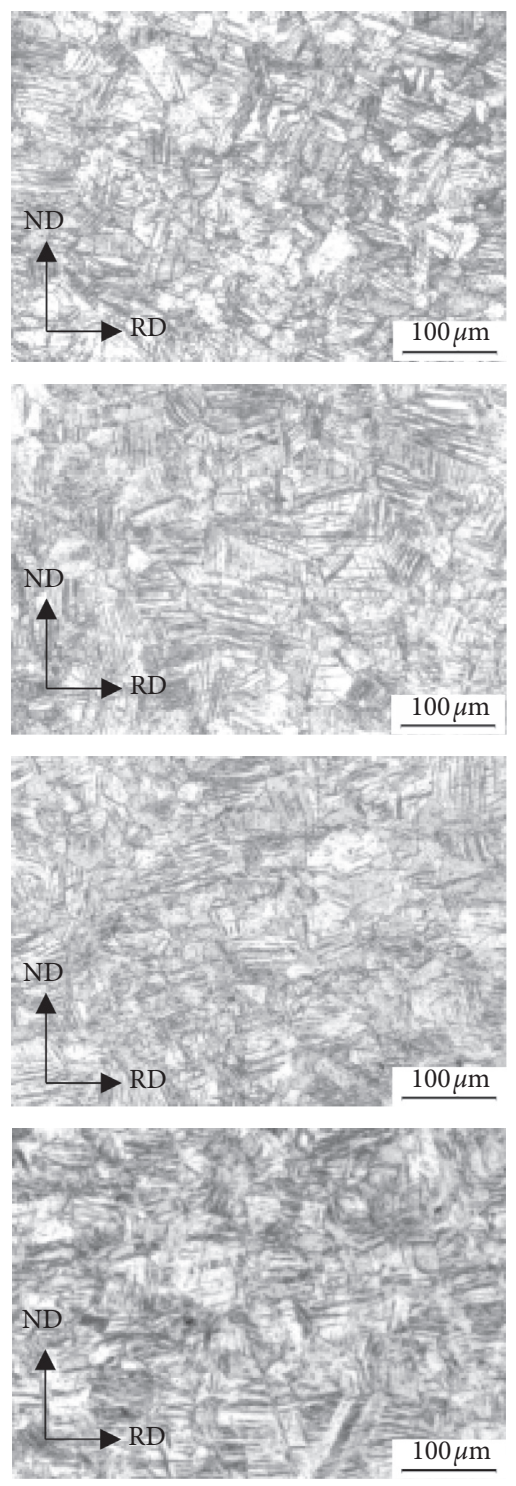

Outside
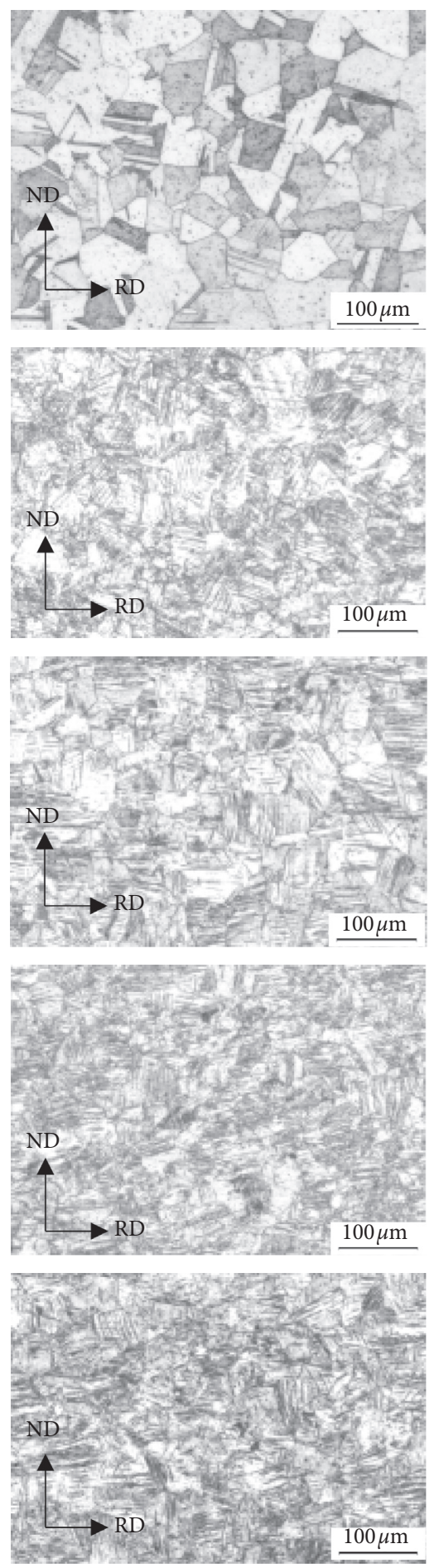

4.2.1. Analysis of Flow Rules in Metal Forming Process. Figure 8 shows the flow of metal. During a rolling cycle, the flow direction at different moments is various. Figure $8(\mathrm{a})$ shows the flow to be rolled, corresponding to section I in Figure 7 , and the metal flows in the rolling direction to extend the tube. Figure 8(b) shows the flow during rolling, corresponding to section III in Figure 7 . It can be seen that the metal flows radially inward so that the diameter of the steel tube and the wall thickness are reduced. This is because the metal which is first in contact with the mandrel is pressed by the mandrel to flow in the rolling direction. Figure 8(c) shows the metal flow in the rebound after rolling, corresponding to section $\mathrm{V}$ in Figure 7, which is rebounded due to the elastic recovery after rolling, and the metal flows radially 


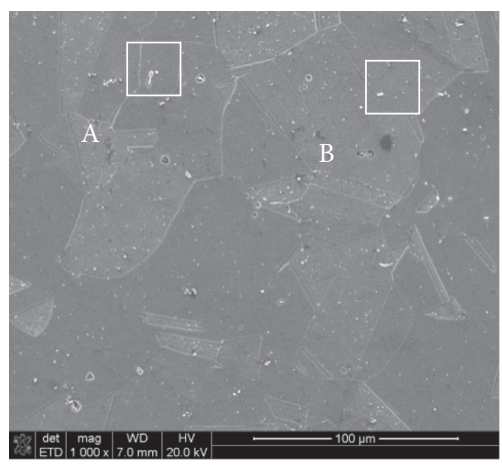

(a)

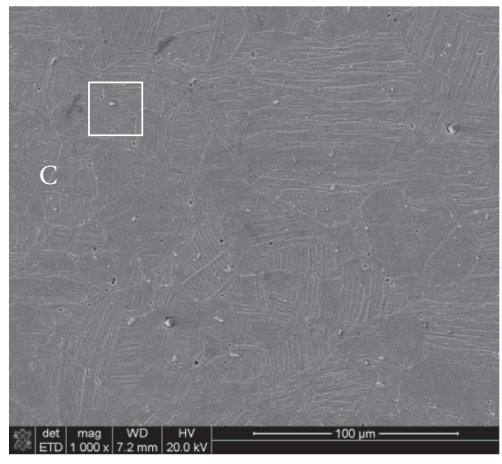

(b)
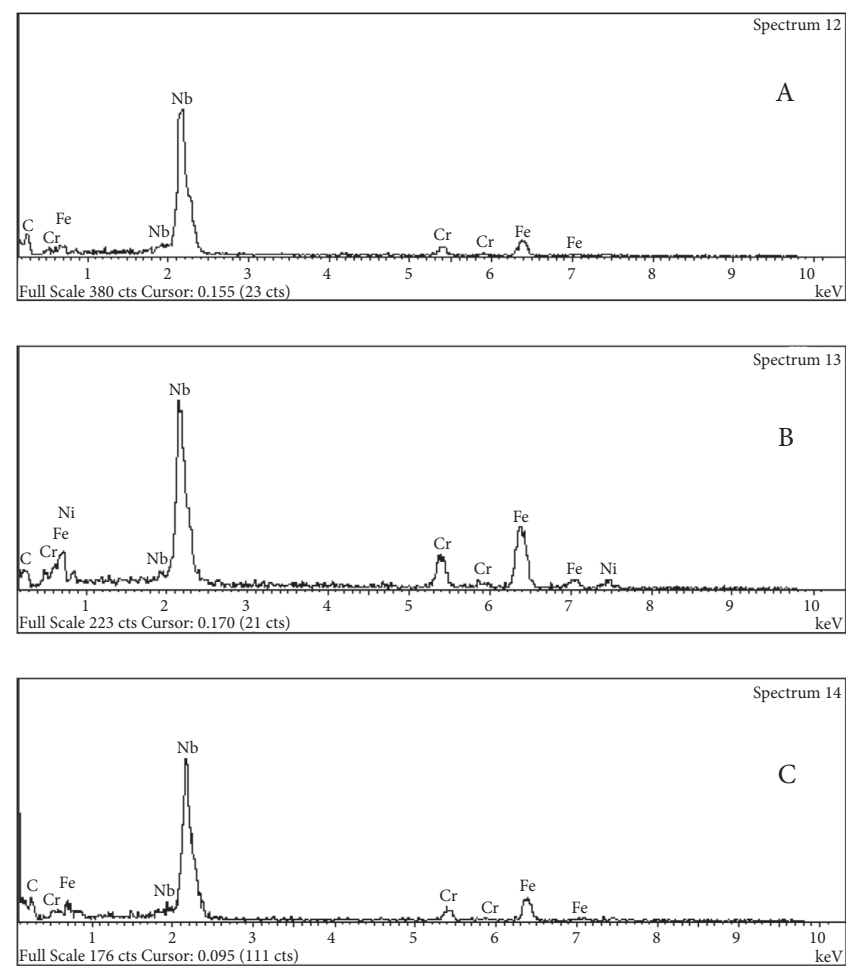

(c)

FIGURE 4: SEM-EDS observations of different deformation sections. (a) SEM photo of section I; (b) SEM photo of section V; (c) EDS results of SEM at each marking point.

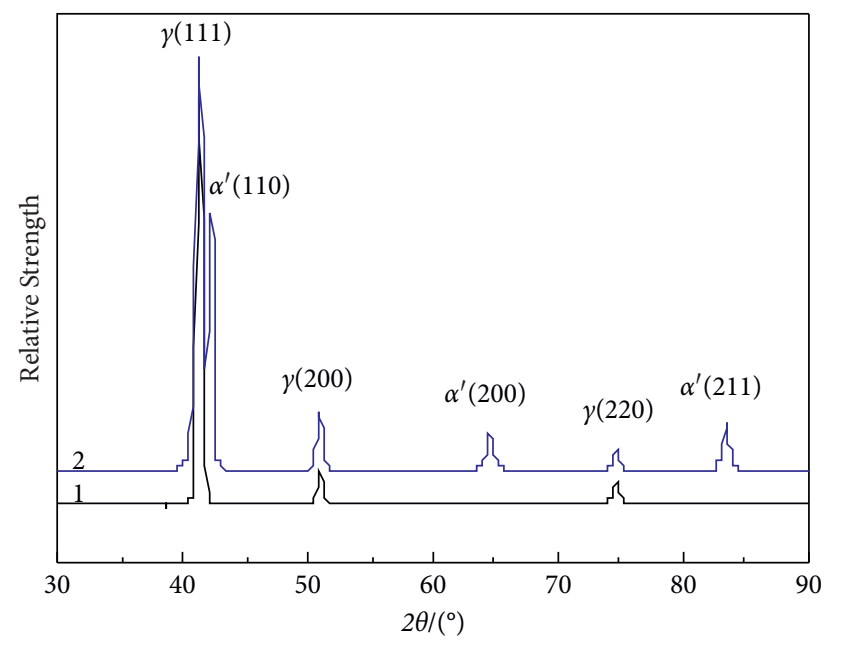

1-Deformation section I

2-Deformation section $\mathrm{V}$

FIGURE 5: XRD patterns of steel tube before and after rolling.

outward. The pilgering is actually a cyclic rolling process. Therefore, as the degree of deformation increases, there will always be some irregularities in the metal flow. That is to say, the direction of metal flow is constantly changing, which also verifies that the slip in the grain of the microstructure obtained by the experiment is irregularly distributed.
4.2.2. Equivalent Stress Analysis. Figure 9 shows a comparison about the equivalent stress of the inner and outer walls at different deformation sections obtained by simulation. It can be seen that the equivalent stress on the inner wall is greater than that on the outer wall, and the maximum phase difference is about $50 \mathrm{MPa}$. The results of the equivalent stress could also show that there is a certain difference in the deformation degree, which echoes the experimental results in Table 3.

\section{Discussion}

In this article, the microstructural evolution of stainless steel tube 347 cold rolled by two-roll pilger was studied by combining simulation with experiment. Specifically, the rolling process was simulated by FEM. The conclusion that the direction of metal flow was irregular distribution was obtained by simulation. The reason why the deformation degree of inner and outer wall of tube was quite different was explained. The simulation results showed that the equivalent stress on the inner wall of the tube was greater than that on the outer wall during rolling, which further verified the conclusion that the grain fragmentation in the rolling process obtained from the metallographic structure begins with the inner wall. The hardening mechanism of cold rolled 347 stainless steel tube was further explained from the aspect of phase transformation by means of SEM and XRD characterization techniques. 


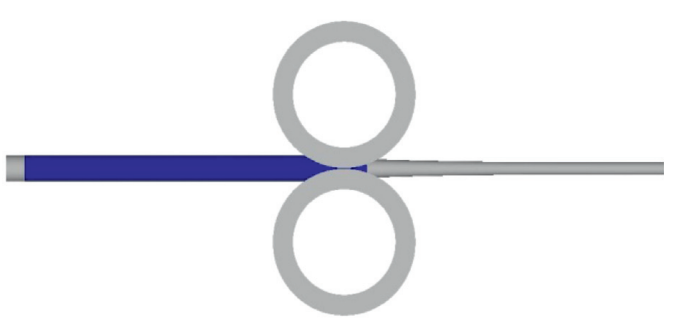

(a)

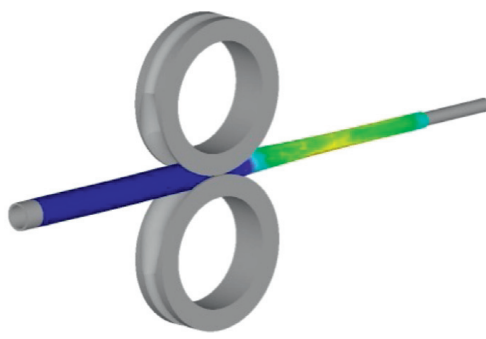

(b)

FIgURE 6: FEM of pilgering.

TABLE 4: Rolling process parameters.

\begin{tabular}{lccccc}
\hline $\begin{array}{l}\text { Rack trips } \\
(\text { times } / \mathrm{min})\end{array}$ & $\begin{array}{c}\text { Gear pitch circle diameter } \\
(\mathrm{mm})\end{array}$ & $\begin{array}{c}\text { Roller diameter } \\
(\mathrm{mm})\end{array}$ & $\begin{array}{c}\text { Rack stroke } \\
(\mathrm{mm})\end{array}$ & $\begin{array}{c}\text { Front turn length } \\
(\mathrm{mm})\end{array}$ & $\begin{array}{c}\text { Rear turn length } \\
(\mathrm{mm})\end{array}$ \\
\hline 60.00 & 336.00 & 376.00 & 951.64 & 60.00 & 90.00 \\
\hline
\end{tabular}

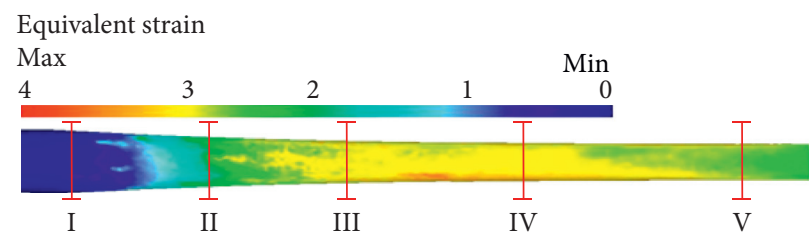

Figure 7: Deformation zone of the tube in simulation.

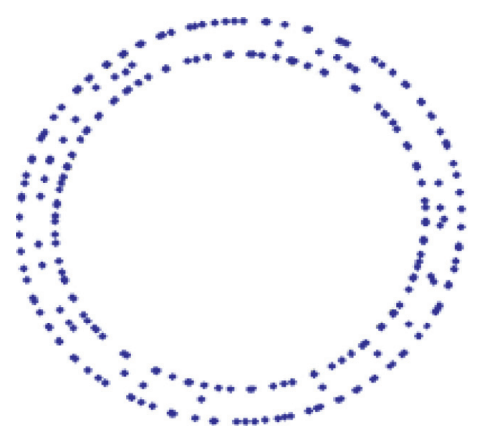

(a)

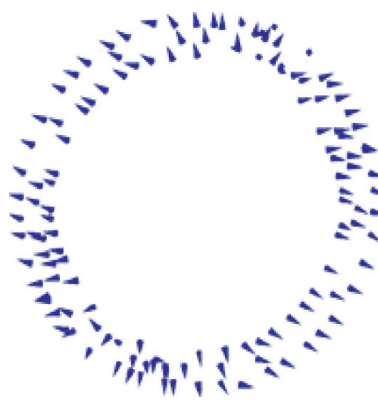

(b)

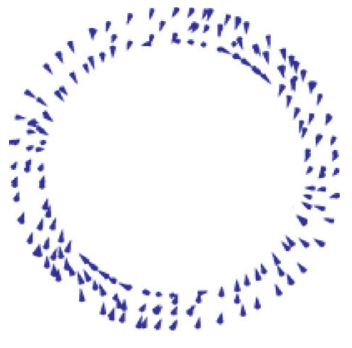

(c)

Figure 8: Metal flowing in an instantaneous at the same location: (a) before rolling, (b) during rolling, and (c) after rolling.

\section{Conclusions}

(1) During the cold rolling process, the grain boundary of the tube blank before rolling was clear, which was a single austenite structure with an average grain size of about 50 microns. With the increase of deformation, a large number of dislocations occurred in the sample, and the dislocation density and entanglement degree increased continuously, resulting in grain fragmentation. In the course of pilgering 347 stainless steel tubes, the internal slip lines of the grains were irregularly distributed, and the inner wall structure was more severely deformed than the outer wall.

(2) By SEM and EDS, it was found that there were a large number of niobium carbide particles precipitated before rolling, and the cold rolling process did not increase the content of niobium carbide. It was analyzed by XRD that a portion of the austenite $\gamma$ phase was transformed into an $\alpha^{\prime}$-martensite phase as rolling progressed.

(3) The pilgering 347 stainless steel tube was simulated by FEM. The results showed that the metal flow direction 


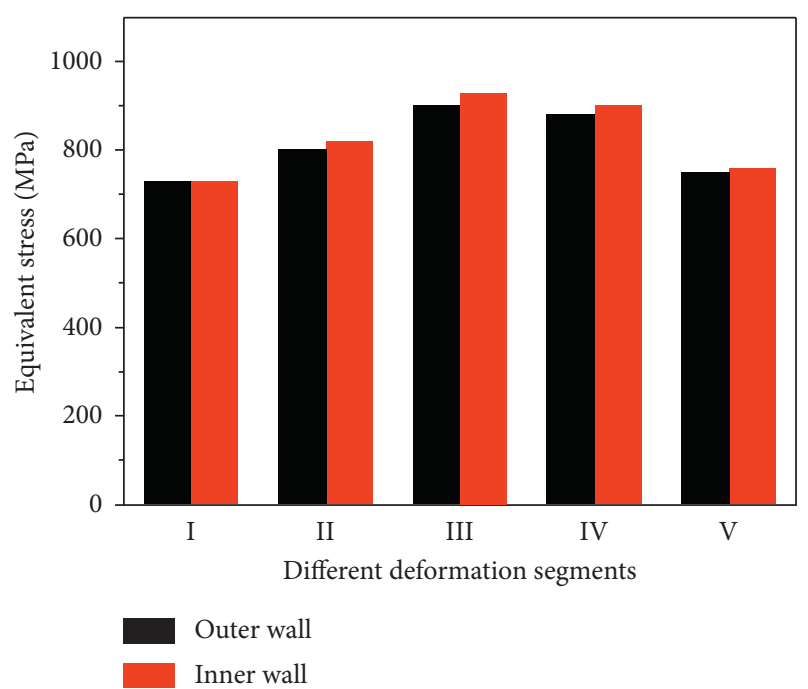

Figure 9: Contrast of inner and outer wall average equivalent stress in the deformation zone.

at any point was in a continuously changing process, and the equivalent stress on the inner wall was greater than that on the outer wall, which could explain to a certain extent the irregular distribution of the sliding direction and the phenomenon that the deformation degree of inner wall was more severe than that of outer wall at the initial section of deformation.

\section{Data Availability}

All data used to support the findings of this study are included within the article. Please contact the authors for more detailed data.

\section{Conflicts of Interest}

The authors declare that they have no conflicts of interest.

\section{Acknowledgments}

This work was supported by the National Key R\&D Program (no. 2018YFB1307902), National Natural Science Foundation of China (no. U1710113), China Post-doctoral Science Foundation (no. 2017M622903), Shanxi Overseas Study Fund (no. 2017-081), Shanxi Key R\&D Project (no. 201703D111003), and Shanxi Provincial "1331 Project".

\section{References}

[1] J. Liu, X. Luo, X. Hu, and L. Siu, "Effect of Ti and Nb micro-alloying on the microstructure of the ultra-purified $11 \% \mathrm{Cr}$ ferrite stainless steels," Acta Metallurgica Sinica, vol. 47, no. 6, pp. 686-694, 2011.

[2] H. Q. Zhang, X. F. Wang, B. L. Wei, and H. Li, "Effect of tooling design on the cold pilgering behavior of zircaloy tube," International Journal of Advanced Manufacturing Technology, vol. 92, no. 3, pp. 1-15, 2017.

[3] B. Leng, S. Ukai, T. Narita et al., "Effects of two-step cold rolling on recrystallization behaviors in ODS ferritic steel," Materials Transactions, vol. 53, no. 4, pp. 652-657, 2012.
[4] B. Lodej, K. Niang, P. Montmitonnet, and J.-L. Aubin, "Accelerated 3D FEM computation of the mechanical history of the metal deformation in cold pilgering of tubes," Journal of Materials Processing Technology, vol. 177, no. 1-3, pp. 188-191, 2006.

[5] S. Mulot, A. Hacquin, P. Montmitonnet, and J. L. Aubin, "A fully 3D finite element simulation of cold pilgering," Journal of Materials Processing Technology, vol. 60, no. 1-4, pp. 505-512, 1996.

[6] H. Abe and M. Furugen, "Method of evaluating workability in cold pilgering," Journal of Materials Processing Technology, vol. 212, no. 8, pp. 1687-1693, 2012.

[7] H. Abe, T. Nomura, and Y. Kubota, "Lubrication of tube in cold pilgering," Journal of Materials Processing Technology, vol. 214, no. 8, pp. 1627-1637, 2014.

[8] S. N. Randall, "Tubular production in the cold Pilger machine," Iron Steel Engineering, vol. 44, no. 8, pp. 109-117, 1967.

[9] H. Abe, T. Iwamoto, Y. Yamamoto et al., "Dimensional accuracy of tubes in cold pilgering," Journal of Materials Processing Technology, vol. 231, pp. 277-287, 2016.

[10] L. Huang, Z. Xu, C. Dai et al., "Three-dimensional FE simulation of multi-strokes cold pilgering of TA18 titanium alloy tube: I theoretical analysis, modeling and validation," Rare Metal Materials and Engineering, vol. 42, no. 3, pp. 524-529, 2013.

[11] L. Huang, Z. Xu, C. Dai et al., "Three-dimensional FE simulation of multi-strokes cold pilgering of TA18 titanium alloy tube: II analysis of plastic deformation behavior," Rare Metal Materials and Engineering, vol. 42, no. 3, pp. 741-745, 2013.

[12] H.-w. Luo, H. Li, and X. D. Fang, "Constitutive analysis in hot working of a $\mathrm{Nb}$ heavily alloyed stainless steel," Journal of Iron and Steel Research, International, vol. 14, no. 5, pp. 179-182, 2007.

[13] S. Y. LiFang, "Induced rupture of AISI 347 stainless steel for automotive in acidic solution," Journal of Iron and Steel Research, vol. 27, no. 2, pp. 70-74, 2015.

[14] B. Yan, Stainless Steel Handbook, vol. 288, Chemical Industry Press, Beijing, China, 1th edition, 2009.

[15] T. Y. Hou, Nonlinear Ultrasonic Characterization of Intergranular Corrosion Sensitivity of 304 Stainless Steel, Dalian University of Technology, Dalian, China, 2016.

[16] G. B. Olson and M. Cohen, "A mechanism for the straininduced nucleation of martensitic transformations," Journal of the Less Common Metals, vol. 28, no. 1, pp. 107-118, 2016.

[17] P. Montmitonnet, R. Logé, M. Chastel, Y. Hamery, J.-L. Doudoux, and J.-L. Aubin, "3D elastic-plastic finite element simulation of cold pilgering of zircaloy tubes," Journal of Materials Processing Technology, vol. 125-126, no. 2, pp. 814-820, 2002.

[18] A. Yağız, G. Mattias, S. Bengt, and L. Lars-Erik, "Finite Element Analysis of cold pilgering using elastic roll dies," Procedia Engineering, vol. 207, pp. 2370-2375, 2017. 